\title{
FILOSOFIA E PARADIGMA EM CÍCERO ${ }^{1}$
}

\author{
Ricardo MONTEAGUDO ${ }^{2}$
}

- RESUMO: Cícero é uma das poucas fontes críticas de textos do pensamento helenístico durante o período da Roma republicana. Ele atualiza a filosofia grega e, concomitantemente, reconhece a superioridade do direito romano. $\mathrm{O}$ espírito prático e guerreiro do povo romano afastava a filosofia, mas a emergência de novos problemas exigia reflexão. Nas disputas políticas e jurídicas, a retórica era um instrumento indispensável. O reaparecimento de estudos retóricos no século XX permitiu que alguns comentadores reconsiderassem a relação entre a retórica e a filosofia, propiciando algumas reflexões sobre o papel de Cícero na historiografia da filosofia.

- PALAVRAS-CHAVE: Retórica; retórica e filosofia; historiografia da filosofia; Cícero; Roma.

Para examinar o crescente descrédito da retórica, evocou-se a mudança de regime no final da Antigüidade, quando as Assembléias beligerantes perderam todo poder político e até judiciário, em proveito do imperador e dos funcionários por ele nomeados.

(Perelman, 1992)

\footnotetext{
1 Texto apresentado na XXV Jornada de Filosofia e Teoria das Ciências Humanas da UNESP História e historiografia da filosofia, Marília, outubro de 2001.

2 Professor do Departamento de Filosofia da FFC da UNESP/Marília.
} 
Bruto, Cássio e Casco [os assassinos de Júlio César], quando empreenderam a libertação de Roma, ou melhor, de todo o mundo, não quiseram que Cícero - esse grande defensor do bem público, se já houve algum - tomasse parte e estimaram seu coração fraco demais para um feito tão elevado.

(La Boétie, 1982)

Alguns períodos da história humana são particularmente fascinantes e se destacam pelo brilho em sua época e pela importância que mantiveram para a posteridade. Um destes períodos cobre o auge e a queda da República Romana, entre a vitória esmagadora sobre Cartago na Terceira Guerra Púnica em 146 a. C. e a instauração do Império com a ascensão de Otávio Augusto César em 27 a. C., após o assassinato de Júlio César em 44 a. C. De um lado, a destruição de Cartago representou o fim da última força capaz de desafiar Roma em todo o mundo conhecido e, de outro, o fim da república enterrou definitivamente a "liberdade antiga", para a qual a retórica tem um papel fundamental.

Na Primeira Guerra Púnica, de 240 a. C., um jovem aristocrata de uma cidade vencida na Magna Grécia foi feito escravo. Seu senhor, porém, surpreendeu-se com sua inteligência e encarregou-o da educação dos filhos. Este preceptor de origem grega, Lívio Andrônico, traduziu a Odisséia para o latim, Odúsia. No entanto, não fez uma tradução no sentido moderno; ele fez uma paráfrase da obra adaptando o metro, a religião grega e os personagens aos padrões romanos. Os deuses mudaram de nome e o personagem principal, Odisseu, tornou-se Ulisses. Essa adaptação se justificava porque quem queria conhecer a Odisséia em grego a lia ou a escutava em grego (como veremos a seguir). Precisamente isso fazia a aristocracia romana - estudava filosofia e retórica gregas na Grécia ou contratava preceptores gregos. ${ }^{4}$

Um século depois, com a destruição total de Cartago na Terceira Guerra Púnica, em 146 a. C., Roma obteve supremacia completa no Mediterrâneo. Segundo Políbio, historiador grego do século II a. C, essa supremacia política e militar se justificava pela superioridade da forma

3 Conforme designação de Benjamin Constant (1985) apontando a oposição entre a "liberdade moderna" e a "liberdade antiga".

4 Cf. Pereira 1989, p.186-99, com a ressalva de que nosso interesse é sublinhar a mudança do estatuto da retórica com a queda da República romana. 
de governo adotada na república romana, que ele chamou de forma mista. Segundo ele, a república romana reunia as vantagens da monarquia, da aristocracia e da democracia e evitava todas as desvantagens de cada uma destas formas. Assim, o Consulado, composto por dois cônsules e renovado anualmente; o Senado, composto pela nobilitas, e o Tribunato, composto por cidadãos plebeus e patrícios eleitos, segundo Políbio, são a melhor organização política que jamais existiu na história, o que pode ser comprovado pela força e pelo fausto atingido pela República Romana (Políbio, 1985, p.331-8).

Contrariamente à sua opinião, entretanto, por todo o século I a. C. Roma é conturbada por disputas políticas internas e guerras civis, enquanto as ameaças externas eram reiteradamente vencidas. O regime misto elogiado por Políbio não era suficiente para lidar com as contradições internas da república. Um recurso institucional de exceção, a ditadura, segundo o qual um cônsul adquiria prerrogativas especiais, foi utilizado duas vezes, por Sila (83-79) e por Júlio César (49-44), e dois triunviratos se sobrepuseram ao Senado, em 60 e após a morte de Júlio César, em 43. Haviam conflitos intensos entre os populares e os optimates, entre os que ganhavam e os que perdiam com a grandiosidade romana. Basicamente, a chegada de grandes levas de escravos para trabalhar reduzia o ganho dos camponeses e pequenos proprietários, que por sua vez forneciam soldados para as batalhas. Era preciso garantir o serviço militar e ao mesmo tempo evitar que os que não iam para a guerra enriquecessem com o trabalho dos escravos. Assim, no Senado, de um lado os generais defendiam os interesses dos populares para não ficarem sem soldados e, de outro, os aristocratas tentavam manter seus privilégios. Por isso foi preciso aumentar o número de optimates para vencer a força cada vez maior dos populares. Cícero, natural de Arpino, era no Senado um homo nouus ("homem novo", um dos novos aristocratas do SPQR - Senatus Populusque Romanus) que tentava manter o equilíbrio entre a tradição e as necessidades presentes. As lutas políticas então eram travadas no Senado, onde o bom uso da eloqüência era fundamental. Daí a importância da sofística e da retórica.

Os optimates tinham o hábito de receber professores gregos e de completar seus estudos na Grécia. Assim, a retórica grega não fazia parte do repertório cultural plebeu. No ano de 93 a. C., contudo, escolas de filosofia e retórica foram fundadas em Roma, onde se passou a estudar em latim. A grande filosofia e a grande retórica chegavam aos populares. No ano seguinte, estas escolas foram fechadas pelos censores e nunca 
mais foram reabertas no período republicano... ${ }^{6}$ Por quê É o que precisamos analisar.

A filosofia era acusada de impiedade por desafiar a moral e os deuses com paradoxos. Catão, o Antigo, dizia que "assim como os médicos podem matar o corpo com drogas, os filósofos podem matar a alma com doutrinas". Algumas décadas antes, em 155 a. C., ele expulsara de Roma o chefe da Academia, Carnéades, porque este era adepto do ceticismo e fizera em dois dias consecutivos dois discursos opostos, um a favor e outro contra a justiça. Quem despreza a justiça pode corromper a juventude romana. As disputas metafísicas efeminam o corpo e envenenam a alma, afastam o cidadão da atenção que este deve ter com a pátria (Plutarco, 1991, v.2, p.291). O argumento, aliás, é grego. O comediógrafo Aristófanes, em As nuvens, satirizava Sócrates mostrando-o como alguém que preferia observar o céu do que empenhar-se em algo sério, desviando os jovens de suas obrigações políticas e religiosas para pensar nas estrelas. As disputas doutrinárias - platônicas, aristotélicas, céticas, epicuristas, estóicas - criavam em Roma um mundo paralelo, mas seu alcance era relativamente pequeno. As querelas filosóficas divertiam o povo cultivado mas não chegavam a ameaçar as instituições, pois a filosofia exige ócio contemplativo.

O constrangimento maior causado pelas escolas foi o ensino da retórica em latim, pois estas disciplinas são instrumentos de luta democrática e política. Desde Górgias e Protágoras, sofistas respeitados porém intensamente combatidos por Platão, há três tipos de retórica, conforme esta se dirija ao passado, ao futuro ou ao presente. A retórica judiciária trata do passado e visa ao justo; a retórica deliberativa decide a respeito do futuro e visa ao bem; e a retórica laudatória ou epidítica lida com o presente e visa ao belo. Note-se que a retórica, ao contrário de questões metafísicas, trata de algo eminentemente prático. Seu objetivo é persuadir, isto é, vencer uma disputa judiciária, ganhar um debate deliberativo ou elogiar e sustentar a beleza de um discurso qualquer. Não importa se a causa é justa, boa ou bela, o que interessa é que a causa pareça justa, boa ou bela. A retórica portanto só se preocupa com as aparências, cabe à filosofia a análise do ser, a procura do justo, do bem e do belo em si mesmos. Daí a oposição entre a filosofia e a retórica, pois esta quer apenas convencer, dispondo os argumentos de modo a favorecer a causa defen-

\footnotetext{
6 Este episódio está relacionado às versões de Rhetorica ad Herennius e à dificuldade na designação de sua autoria, por isso é discutido nas introduções eruditas da obra (Cf. Caplan, 1989; Achard, 1989; Pereira, 1989, p.194, nota 22).
} 
dida ou prejudicar a causa atacada, e a outra (a filosofia) pretende alcançar a verdade.

Para a retórica, chama-se "lugar" um argumento utilizado em diversas ocasiões com objetivos diversos. Um dos "lugares-comuns" na Grécia era o "elogio de Helena", muito explorado pelos sofistas e professores de retórica. Chegou a nós um discurso de Górgias explorando este lugar, Elogio a Helena, no qual a causadora da Guerra de Tróia é defendida da censura de ter sido conivente com o seqüestro de que fora vítima. Segundo este discurso, há quatro causas para Helena ter sido levada: ou trata-se de uma deliberação dos deuses, ou ela foi presa pelo amor, ou foi levada à força, ou foi persuadida por palavras. Se os deuses decidiram, é o destino e ela nada poderia fazer. Se ela foi levada à força, a força dela era menor e ela cedeu por necessidade. Se Helena foi presa pelo amor, a causa é a visão da beleza, e como bela é a lei boa e boa a lei que conduz à vitória, sua alma grega deixou-se vencer pela visão da natureza bela (já que uma grega não pode amar verdadeiramente ou ser amiga de um bárbaro). Enfim, se Helena foi persuadida por palavras, então foi forçada pelo discurso, não pôde controlar as paixões (pathos), pois o "discurso molda a alma da maneira que quer" (Górgias, 1999, p.18). Helena não poderia resistir a nenhuma destas causas e portanto não é culpada. Observe-se assim que o poder do discurso equivale ao dos deuses, para quem sabe usá-lo.

No âmbito clássico grego, quanto à relação entre filosofia e retórica, a Academia de Platão e o Liceu de Aristóteles tinham um adversário comum, a escola de Isócrates, que também fora aluno de Sócrates. Platão considera que o filósofo tem a finalidade de buscar o bem, o belo e o justo, que é preciso evitar as ilusões da aparência e da sensibilidade para reconhecer a essência e a inteligibilidade. O único caminho é o esforço dialético ascendente da filosofia. Ora, como a retórica só quer persuadir, ela se preocupa apenas com a aparência, então é imoral. Aristóteles, ao contrário, considera que a filosofia usa o discurso como instrumento na procura da verdade, enquanto a retórica quer apenas persuadir sem se importar com a verdade. Assim, a retórica é amoral e não imoral, pois pode persuadir tanto para o bem quanto para o mal, mas o discurso verdadeiro é mais persuasivo do que o discurso falso. Por isso, o filósofo precisa conhecer as técnicas da retórica para não se deixar enganar pelos que não são filósofos mas conhecem a técnica. Isócrates, por outro lado, considera que não existe filosofia sem um discurso que a apresente, então a filosofia que visa ao bem e a retórica que ensina a falar bem são dois aspectos da mesma questão. Fica abolida a distinção platônico- 
aristotélica entre verdade e verossímil. A retórica não é nem imoral nem amoral, pois assim como a filosofia também depende de um ponto de partida consensual para ter eficácia. Assim, se pode haver um mau uso da retórica, pode também haver um mau uso da filosofia. Desta forma, Isócrates dá estatura filosófica aos sofistas combatidos por Platão e por Aristóteles.

Isto posto, voltemos a Roma. As escolas ensinavam a técnica retórica aos plebeus, que passavam a dispor deste instrumento do bem falar no momento em que se discutia, tanto no Senado quanto na Tribuna, o bem fazer. Compreende-se então por que as escolas foram fechadas em um ano e o ensino da retórica foi proibido. Entretanto, diversos manuais de retórica passaram a circular clandestinamente. Tais escolas e tais manuais tiveram o mérito de criar um vocabulário latino para termos retóricos gregos. ${ }^{7}$ Um deles chegou a nós, o Rhetorica ad Herennium. Deste período resta-nos também um texto do jovem Cícero, De inventione. Décadas mais tarde, Cícero escreveu obras mais completas sobre retórica em que funda a teoria (De oratore), problematiza a elocução (Orator) e traça uma história da retórica (Brutus). O arpinate também escreveu obras de filosofia, tanto obras em que discute conceitos filosóficos - como o De natura deorum e De officiis -, quanto obras de divulgação - como Definibus e De divinatione. A questão fundamental da disputa entre filosofia e retórica foi abordada diversas vezes.

No De oratore, por exemplo, Cícero afirma que "surgiram pensadores engenhosos que se aborreciam com a vida política e por isso desprezavam a disciplina típica desta vida, isto é, a retórica; o primeiro foi Sócrates" (Cícero, 1956, v.3, § 59). Essa passagem é notável porque mostra que não é a concepção de verdade ou episteme, não é a desconfiança da aparência, mas especialmente o desdém pela política que afasta Sócrates da retórica. A filosofia sem a retórica, portanto, é incompleta, porque ignora a vida política, a vita activa. ${ }^{8} \mathrm{~A}$ filosofia que desconsidera a política é incompleta, a sabedoria sem a ação é inútil e o que é inútil nem sempre é inofensivo. "Sócrates separou duas coisas estritamente unidas, a ciência do pensar com sabedoria e a do bem falar" (ibidem, $\S 60$ ). Ora, a

7 Plutarco reconhece este grande mérito de Cícero: "Foi ele [Cícero], pelo que se diz, o primeiro a dar em latim as noções de imaginação (phantasía), estado de dúvida (epoché), acordo (synkatháthesis), percepção (katálepsis), e também de átomo, indivisível, vazio e outros do gênero. Tudo fez para torná-los inteligíveis aos romanos, seja através de metáforas, seja através de termos próprios" (Plutarco, 1991, v.5, p.68).

$8 \mathrm{Em}$ A condição humana, H. Arendt comenta a importância da vita activa na Antigüidade e os reflexos de seu enfraquecimento na modernidade. 
maiêutica socrática se engana quando considera que não é preciso falar corretamente para pensar com adequação. Assim, o engenho de Sócrates também é retórico. "Daí surgiu aquela conhecida separação entre a língua e o coração, absurda, inútil e reprovável, segundo a qual alguns deveriam nos ensinar a ser sábios e outros a falar" (ibidem, § 61). Note-se que, sem a língua, o coração não se manifesta sabiamente, trata-se de uma separação que não se encontra nos homens, que não convém aos homens.

As obras filosóficas de Cícero são, em geral, como no caso de Lívio Andrônico, paráfrases comentadas da filosofia grega. Como não conhecemos os textos a que ele teve acesso, a obra do arpinate parece escapar de esquemas interpretativos unívocos, pois desenvolve idéias em várias direções e apresenta doutrinas que não combinam entre si. Trata-se do uso de exemplos (exempla em latim, paradeigma em grego), em sentido retórico, isto é, a exploração de "lugares" com finalidades precisas, que no entanto temos dificuldade para reconhecer. Todo argumento procede por analogia (inductio) ou por dedução (raciocinatio) e, assim como suas fontes (loci, lugares), obedecem aos critérios da inuentio, da escolha, procura ou descoberta de elementos a serem reunidos adequadamente no discurso, em função de uma finalidade. ${ }^{9}$ Em outras palavras, como a filosofia e a retórica caminham sempre juntas, a apresentação de uma doutrina segue as regras da técnica retórica e não se dissocia da finalidade do orador ao apresentá-la. Por isso, a idéia de tradução não se coloca, pois a conversão de um texto para outro idioma implica uma alteração do auditório, isto é, uma mudança do público-alvo e, assim, uma reacomodação dos argumentos. Uma doutrina só pode portanto ser comentada, a tradução implica uma transposição. Por isso, as apresentações de idéias filosóficas em Cícero são discursos retóricos modelares (dialogados ou não). Mas esta é justamente a questão: não é porque se trata de um discurso retórico que se anula a presença da filosofia. O orador (ou escritor) precisa cuidar da recepção da obra. Ao reunir retórica e filosofia, Cícero preocupava-se com o que hoje chamamos interpretação e que na Antigüidade era assunto da retórica.

No Paradoxa stoicorum (Paradoxos dos estóicos), por exemplo, Cícero procura demonstrar proposições estóicas, que adquirem a designação de paradoxos porque contrariam a opinião comum. Após elogiar a eloqüência, que pode tornar grave e sério até mesmo o que é grosseiro e

9 Todo orador tem cinco tarefas em seu discurso: inuentio (seleção de assuntos, argumentos e exemplos), dispositio (ordenação das partes), elocutio (adequação de linguagem a sua finalidade), memoria (métodos de recordação) e pronuntiatio (gestos e tom de voz). 
indiferente, Cícero afirma: "Minhas teses parecem-me tão socráticas quanto estes paradoxos, e verdadeiras" (Cícero, 1971, v.1, § 4). A verdade sem a eloqüência perde sua força - mas esta afirmação é mais eloqüente do que verdadeira. Ao analisar o primeiro paradoxo, "a honestidade é o único bem" (quod honestum sit id solum bonum esse), assevera que quem estima somente o dinheiro, o luxo e as riquezas, jamais se acalma. O ganancioso vê-se forçado a procurar estes bens todo o tempo, $\mathrm{e}$, ademais, tortura-se com a inveja dos que os possuem e com o medo de perder o que tem. Tais bens todavia são frágeis porque dependem da fortuna (do destino) e das circunstâncias, ao passo que a virtude e a honestidade são os verdadeiros bens porque independem dos acidentes. Recebemos "de um deus ou da natureza uma alma cuja excelência e divindade ninguém iguala" (ibidem, v.3, § 14). Esse é o verdadeiro bem que exige virtude e honestidade para ser compartilhado e que merece elogios. Por outro lado, os prazeres e diversões, que também são circunstanciais, mesmo que sejam bens, como querem alguns, não são dignos de elogios. Ninguém se orgulha de proclamar publicamente que teve algum determinado prazer, trata-se de algo que não é compartilhado, ou que, quando o é, depende de honestidade. Portanto o verdadeiro bem é viver honestamente. $\mathrm{O}$ que encontramos neste trecho é um discurso retórico em defesa de uma hipótese moral. As questões propriamente filosóficas - o que é alma, por que os deuses ou natureza a atribuíram ao homem, por que a alma permite partilhar a honestidade, entre outras que são sugeridas não são aprofundadas. Temos a impressão de que um discurso contrário seria equivalente. A defesa estóica parece convidar o leitor à reflexão cética.

Em outra obra, De officiis (Dos deveres), a moral estóica é aprofundada e desta vez o exercício retórico cede à reflexão filosófica. Ali Cícero afirma que "é idêntica a regra da utilidade e da honestidade" (Cícero, 1999, v.3, § 74, p.160). A convergência do honesto e do útil para a justiça é detidamente analisada. O ponto de partida é o seguinte:

O fundamento da justiça é a confiança, ou seja, a verdade e a constância em palavras e acordos. Assim, embora isso possa parecer muito grosseiro a alguns, ousemos imitar os estóicos, que dedicadamente investigaram a origem das palavras, e acreditemos na fé (fides), assim chamada porque faz (fiat) o que foi dito. (Ibidem, v.1, 23, p.14)

Note-se que o vínculo entre a justiça e a confiança em palavras e acordos é de fundamento. Sem tal confiança, a justiça perde seu fundamento e inexiste. O honesto e o útil se amarram entre si por meio da con- 
fiança recíproca, sem a qual se anulam. Assim, o meio por excelência da justiça é a retórica e não mais a filosofia, pois esta busca a verdade e aquela garante a fé. Todavia, o que confere autoridade à confiança na palavra? O bem comum, a utilidade comum (communis utilitatis). Esse é o elemento que une os homens, caso contrário a sociedade se dissolve. "Deve haver em todos o propósito único de fazer com que o interesse de cada um coincida com o interesse geral; pois se alguém o reservar só para si provocará a dissolução do consórcio humano" (ibidem, v.3, § 26, p.137). Donde "estamos todos agrupados sob uma única lei de natureza que nos proíbe de prejudicar os outros". Há então uma lei natural que implica a defesa do bem comum, há por este intermédio uma base natural para a justiça. Essa é muito sumariamente a visão estóica que Cícero comenta, aprofunda e desenvolve no De officiis.

Seus comentários corrigem a visão original, mas tais correções são inacessíveis ao rigor histórico moderno, ou melhor, à retórica da historiografia filosófica moderna porque não dispomos de suas fontes.

Cícero se empolgara com o ensino cético da Nova Academia, então muitos comentadores ${ }^{10}$ consideram-no por isso um cético que, a exemplo de Carnéades, vê todo discurso filosófico como algo que pode ser retoricamente combatido com outro discurso de igual força e sentido contrário. Outros, ${ }^{11}$ já que Cícero também teve professores estóicos, como Possidônio, apontam-no como estóico, pois há textos em que as proposições e a ética desta escola são defendidas, como o De officiis, em que a defesa do Senado e da República apóia-se num comentário sobre a obra de Panécio e na exposição da concepção estóica de direito natural.

Os criadores da concepção moderna de história da filosofia, Kant e Hegel, consideram Cícero superficial, pois não encontram no conjunto de sua obra uma unidade filosófica. Hegel, por exemplo, nas Lições sobre a filosofia da história, afirma: "Cícero foi estóico, se bem que é muito difícil distinguir em sua exposição o princípio da moral estóica do princípio da moral peripatética" (Hegel, 1977, v.2, p.346). E apresenta sua filosofia como "uma filosofia popular e superficial, sem nenhum valor especulativo, mas que tem, pela cultura geral a que se refere, o interesse e a importância do homem que nela se acha inspirando-se em si mesmo como um todo, em sua experiência interior e exterior, e em seu presente em geral" (ibidem, v.3, p.165). Nesta obra, Hegel recorre freqüentemente ao De officiis e ao De natura deorum de Cícero como fonte

10 Entre outros, Maria Helena da Rocha Pereira e Osvaldo Porchat.

11 Entre outros, Milton Valente e Hegel, como veremos a seguir. 
historiográfica da filosofia antiga ${ }^{12}$ e também o apresenta como um dos maiores "desenvolvedores da lógica aristotélica" (ibidem, v.2, p.324), certamente se referindo às obras retóricas. Sabemos todavia, nesse caso a exemplo de Platão, o desdém que Hegel nutria pela retórica, que se torna um problema lógico. Até a passagem do tempo obedece a uma lógica peculiar, à lógica dialética. A frase que caracteriza seu pensamento, "tudo o que é real é racional, tudo o que é racional é real", parece recuperar a Escola eleata contra os sofistas.

Kant, por sua vez, também desconfiava da retórica, procurava as condições de possibilidade da ciência e da razão para além de toda contingência, de todo acidente. Na Fundamentação da metafísica dos costumes, Kant (1980, p.121) define a filosofia popular como uma doutrina que adere mais ao gosto popular do que às exigências da razão. Cícero escreveu obras de divulgação e também obras de reflexão, preocupando-se com a recepção do público. É de se perguntar se a condição transcendental da razão não exige uma filosofia da linguagem. ${ }^{13}$

Um debate recente a este respeito ocorreu entre Chaim Perelman e Armando Plebe. Segundo Perelman (1990, p.1), desde Descartes a retórica foi alijada da filosofia e agora é preciso resgatá-la para seu lugar. Perelman (ibidem, p.31 ) acusa Descartes, Kant e outros de ignorarem a retórica em sua argumentação considerando-a inconsistente, frágil, mostrando que ela recorre a provas exteriores ao argumento (provas que Aristóteles designava "não-técnicas", como a reputação do orador, o senso comum etc.). Ele cita, por exemplo, um trecho da Crítica do Juízo de Kant: "A arte oratória enquanto arte de servir-se da fraqueza humana para seus próprios fins ... não merece estima alguma" (apud Plebe, 1978, p.110). Por sua vez, Plebe lembra uma passagem de Aristóteles na Retórica (Aristóteles, 1932, I, 1355b): "A função da retórica não é persuadir, mas estudar os meios técnicos da persuasão que existem em qualquer argumento". A distinção de racionalidade e emotividade na argumentação feita por Kant é transferida para o tipo de auditório pressuposto, vinculando a razão à pressuposição de um auditório universal. Ao contrário, Kant separa a retórica não-filosófica da retórica lógica e conceitual, graças à qual se pode plantar uma "convicção", por exemplo, o imperativo

12 Fazer uma análise do uso que Hegel faz de Cícero por oposição a outras fontes do mesmo assunto seria interessante para o âmbito do estudo da historiografia da filosofia, mas é um esforço que ultrapassa os limites deste trabalho.

13 É de se perguntar se as condições transcendentais da razão não exigem uma linguagem transcendental, isto é, se a filosofia não precisa ser antecedida por uma filosofia da linguagem. Cf. Prado Júnior, 1998. Esta preocupação também está presente em Todorov, 1977. 
categórico (Plebe, 1978, p.112). Portanto, segundo Plebe, embora Kant aparente ser inimigo da retórica e Perelman se apresente como seu defensor, é Kant que sugere como lidar filosoficamente com a retórica, não como uma psicagogia vinculada ao público, mas como pressupostos transcendentais válidos tanto para o discurso lógico quanto para o discurso filosófico. ${ }^{14}$ Ora, o que nos parece especialmente interessante nesta polêmica entre Perelman e Plebe é que nela se manifesta uma nova maneira de se lidar com a história da filosofia sem ignorar o aspecto retórico. Não se trata portanto de separar os amigos e os inimigos da retórica, mas pelo contrário, trata-se de verificar como o pensamento retórico transparece à sua maneira em cada filósofo.

O que ocorreu recentemente foi o renascimento de estudos retóricos e o ressurgimento das discussões sobre a relação entre a retórica e a filosofia. Com isso, os pensadores que apresentam em sua obra uma reflexão filosófica da retórica ressurgem no âmbito da história da filosofia. Esse é o caso de Isócrates na Grécia, e de Cícero em Roma. De um lado, Isócrates é um pouco anterior ao primeiro historiador da filosofia, o autor da Metafísica, e não tem nenhuma obra historiográfica, ao contrário de Cícero, como vimos. Dessa forma, Cícero renasce enquanto problema historiográfico e filosófico. Ora, a exemplo dos grandes pensadores gregos, Cícero pensa a filosofia e a retórica no seio de uma totalidade física, ética e política. Assim, defender o epicurismo e o culto ao prazer, por exemplo, é perigoso para a república romana, trata-se aí de uma retórica anti-republicana que precisa ser combatida. Eis uma doutrina nociva. Ora, se uma doutrina deve ser combatida, outro referencial doutrinário precisa servir de apoio. Caso o apoio seja exclusivamente cético, caso se trate apenas de discurso e contradiscurso, a legitimidade de ambos está garantida e o debate convém apenas aos filósofos ociosos que observam as estrelas. Não se trata, entretanto, de um combate que visa apenas ao divertimento aristocrático ou ao exercício da prática retórica. Trata-se, como diríamos hoje, ou melhor, como disse Rousseau na Carta a d'Alembert, de "uma verdade prática importante para todo um povo" (Rousseau, 1993, p.30). Essa verdade prática é então objeto tanto da filosofia quanto da retórica. Assim, os adendos e correções feitos por Cícero a Possidônio no De officiis não são de ordem exclusivamente retórica nem de ordem exclusivamente filosófica, como sabemos pelas circunstâncias em que a obra foi escrita. Trata-se da relação entre a filosofia e a retórica em estado bruto. Parece-me, contudo, que para destrinçar essa

14 A exposição do problema e a crítica de Armando Plebe estão em Plebe, 1978, p.109-13. 
relação na obra de Cícero, precisamos de certa maneira rever a concepção historiográfica tanto de Kant quanto de Hegel, aliás ambas diferentes entre si, embora hegemônicas. Em outras palavras, creio que entender a filosofia de Cícero é desafiá-lo retoricamente sem cair no vazio cético, e entender a retórica de Cícero é desafiá-la filosoficamente sem cair na ingenuidade dogmática estóica. Muitos já o fizeram, a questão agora é reincorporar a disputa entre filosofia e retórica no seio da historiografia filosófica. Cícero, Rousseau e Nietzsche, entre outros, adquiririam outro estatuto na história da filosofia. Acabaria a falsa independência do historiador: todos têm seu "lugar", em sentido retórico. Isso equivale a duplicar nosso trabalho e nossas preocupações, mas temos o benefício de evitar a um tempo tanto os totalitarismos quanto as ideologias.

MONTEAGUDO, R. Philosophy and paradigm in Cicero. Trans/Form/Ação (São Paulo), v.25, p.53-65, 2002.

- ABSTRACT: Cicero is one of the sources of texts of Hellenistic thought in the period of the Roman Republic. He updates Greek philosophy and, at the same time, recognizes the superiority of Roman right. The practical and bellicose Roman spirit took distance from philosophy, but new problems demanded reflection. In political and judicial disputes, rhetoric was an essential instrument. The 20th century revival of rhetorical studies allowed some commentators to reconsider the relationship between rhetoric and philosophy, leading to new reflections about Cicero and the historiography of philosophy.

- KEYWORDS: Rhetoric; rhetoric and philosophy; historiography of philosophy; Cicero; Rome.

\section{Referências bibliográficas}

ACHARD, G. Introduction. Rhétorique à Herennius. Paris: Belles Lettres, 1989. ARENDT, H. A condição humana. Rio de Janeiro: Forense Universitária, 2000.

ARISTÓFANES. As nuvens. In: Sócrates. São Paulo: Abril, 1980. (Os Pensadores).

ARISTÓTELES. Rhétorique. Paris: Belles Lettres, 1932.

CAPLAN, H. Introduction. Rhetorica ad Herennius. Cambridge: Loeb Classical Library, 1989.

CÍCERO. De oratore. Paris: Belles Lettres, 1956. 3v. 
CÍCERO. Paradoxa stoicorum. Paris: Belles Lettres, 1971.

Dos deveres (De officiis). São Paulo: Martins Fontes, 1999.

CONSTANT, B. Da liberdade dos antigos comparada à dos modernos. Filosofia Política. Porto Alegre, n.2, 1985.

GÓRGIAS. Elogio de Helena. Cadernos de Tradução (São Paulo), n.4, Departamento de Filosofia, FFLCH-USP, 1999.

KANT, I. Fundamentação da metafísica dos costumes. In: Kant. São Paulo: Abril, 1980. (Os Pensadores).

. Crítica da faculdade do juízo. Rio de Janeiro: Forense Universitária, 1995.

HEGEL, G. W. F. Lecciones sobre la historia de la filosofia. México: Fondo de Cultura Económica, 1977. 3v.

LA BOÉTIE, E. Discurso sobre a servidão voluntária. São Paulo: Brasiliense, 1982.

PEREIRA, M. H. R. Estudos de história da cultura clássica. Lisboa: Calouste Gulbenkian, 1989. v.2: Cultura romana.

PERELMAN, C., OLBRECHTS-TYTECA, L. A nova retórica. São Paulo: Martins Fontes, 1990.

PERELMAN, C. Retóricas. São Paulo: Martins Fontes, 1992.

PLEBE, A. Breve história da retórica. São Paulo: EPU, Edusp, 1978.

PLEBE, A., EMANUELE, P. Manual de retórica. São Paulo: Martins Fontes, 1992.

PLUTARCO. Vidas paralelas. São Paulo: Paumape, 1991. 5v.

POLÍBIO. História. Brasília: Editora da UnB, 1985.

PORCHAT, O. Ceticismo e argumentação. In: PORCHAT, O. Vida comum e ceticismo. São Paulo: Brasiliense, 1994.

PRADO JÚNIOR, B. A força da voz e a violência das coisas. In: ROUSSEAU, J.-J. Ensaio sobre a origem das línguas. Campinas: Editora da Unicamp, 1999.

ROUSSEAU, J.-J. Carta a d'Alembert sobre os espetáculos. Campinas: Editora da Unicamp, 1993.

TODOROV, T. Théories du symbole. Paris: Seuil, 1977.

VALENTE, M. A ética estóica em Cícero. Caxias do Sul: EDUCS, 1984. 